\title{
How institutional and interpersonal variables impact international L2 students' language gains at university
}

\section{Bart Deygers}

KU Leuven, Centrum voor Taal \& Onderwijs, Blijde-Inkomststraat 73000 Leuven, Belgium

\section{A R T I C L E I N F O}

\section{Article history:}

Received 15 February 2018

Received in revised form 9 May 2018

Accepted 17 May 2018

\section{Keywords:}

Language gains

International L2 students

Mixed-methods

Longitudinal

Academic socialization

\begin{abstract}
A B S T R A C T
As higher education has grown into a global enterprise, international students have become an integral part of the student population at many universities. Given this reality, it is striking that there are considerable gaps in our knowledge of whether and why international students make language gains, or fail to do so. In order to address these voids in research, this study employed a longitudinal mixed-methods design to measure oral and written gains made by international L2-Dutch students studying in universities in Flanders over an eight-month period. It also sheds light on the institutional and social contexts of the participants, as measured by longitudinal in-depth interviews. The quantitative data indicate that the participants made no demonstrable gains except on one sole indicator of written fluency, and the qualitative findings reveal that linguistic readiness, perceived linguistic inferiority, and a lack of access to the L1 community hampered students' opportunities and willingness to engage in meaningful interaction. This study offers no immediate reason to presume that rich input alone yields language gains, even with advanced learners in an academic context. Rather, it reaffirms the hypothesis that language learning in a naturalistic setting is driven by meaningful interaction and a sense of belonging.
\end{abstract}

(C) 2018 Published by Elsevier Ltd.

\section{Introduction}

Following the exponential increase of international students, institutions of higher education worldwide have set minimum language entrance requirements for aspiring students who speak the language of instruction as an L2. Little attention has been given, however, to what happens to international L2 students after admission (a notable exception is Read, 2016). The writing gains made by these students have been the subject of only a few studies (Knoch, Rouhshad, Oon, \& Storch, 2015), and no peer-reviewed research has measured this population's speaking gains. This is striking for two reasons. First, since international students use the L2 primarily as a medium - not the goal - of instruction (Knoch et al., 2015), study of their language gains could yield important data regarding naturalistic language acquisition. Secondly, studying post-admission language gains may offer vital information to policy makers and instructors, who often bank on international L2 students making post-admission language gains (Deygers, Van den Branden, \& Van Gorp, 2017).

The current article examines whether international L2 students make spoken and written gains during their first academic year. It explores the institutional context and interpersonal relationships of international students to investigate why these

E-mail address: bart.deygers@kuleuven.be. 
factors might influence language gains. The results further the knowledge of L2 acquisition processes and yield insights for educational policy development and practice.

\section{Literature review}

International students - the focal group of this study - differ from study abroad students and Erasmus students in several ways. Study abroad (SA) students typically stay in an L2 context for a predetermined amount of time as part of their curricular requirements for the very purpose of improving their proficiency in the target language (Engle \& Engle, 2003). Typically, the 325,000 SA students per year (NAFSA, 2017) receive additional language instruction during their stay. Similarly, the 1.7 million students per year on an Erasmus exchange pursue adventure, language learning, and meeting new people (European Commission, 2015) while attending courses as part of their curriculum at another European institution for one or two semesters. Often, Erasmus students will also attend additional language courses to master the language of instruction. Both Erasmus and SA students remain in touch with their home institution throughout their stay, and then return home.

International students, by contrast, are disconnected from any home institution and simply register as regular students at their chosen university. For these students, learning the language of instruction is not necessarily their goal, but rather a condition of enrollment. Often, their motivations for studying internationally are markedly different from SA or Erasmus students; they are either pulled towards economic opportunities and career benefits, or pushed away from war or other threats (Chirkov, Vansteenkiste, Tao, \& Lynch, 2007).

In the second language acquisition (SLA) research literature, the language gains of SA students (see the special issue edited by De Costa, Rawal, \& Zaykovskaya, 2017) and Erasmus students (e.g., Llanes, Tragant, \& Serrano, 2012; Serrano, Tragant, \& Llanes, 2012), have received more attention than those of international students. This is striking, since international students-who number 3.3 million per year (OECD, 2017) - outnumber and generate far more revenue for universities than the other two categories (Cantwell, 2015). By shedding light on the language gains made by international students, this paper thus directs attention to a sizeable yet under-researched population.

\subsection{Measuring international L2 students' language gains}

Within the limited body of existing research on international students' language gains, most studies include participants who received additional language support (e.g., Green, 2004; Llanes et al., 2012; Serrano et al., 2012). In many contexts however, international students attend academic courses in the L2 without taking additional language classes (Knoch et al., 2015).

Perhaps the only research into language gains made by international L2 students who did not receive L2 language support was conducted at the University of Melbourne, Australia. The results of studies there showed limited writing gains after one semester (Storch, 2009), one year (Knoch, Rouhshad, \& Storch, 2014), and three years (Knoch et al., 2015). Significant gains were found for only one indicator of fluency: the number of words written within a 30-min time frame $(p<.005)$. To date, speaking gains made by international L2 students without supplementary language instruction have not been researched. In contrast, the SA literature has extensively reported on both written and spoken gains. Even though SA demonstrably yields overall language gains (Yang, 2016 reported an effect size of $d=0.8$ ), and gains in oral fluency even after stays as short as four months (Huensch \& Tracy-Ventura, 2017) or four weeks (Tavakoli, 2018), its effects on language proficiency indicators are somewhat ambivalent. Study abroad experiences have been shown to beneficially impact oral fluency and lexical complexity, but not necessarily pronunciation, or accuracy in the spoken modality (Serrano et al., 2012). In the case of writing, both gains and zero growth results have been reported (Llanes et al., 2012). Studies reporting writing gains include Serrano et al. (2012) and Pérez-Vidal (2014). The former found significant gains for written fluency, syntactic complexity, lexical richness, and accuracy over the course of two semesters, while the latter reported gains in written lexical complexity and written fluency.

SA has also been found to benefit lexical development. Using the Vocabulary Levels Test, Briggs (2015) reported moderate lexical gains over thirteen weeks, while Tavakoli (2018), using CALF measures (short for complexity, accuracy, lexis and fluency), found increased lexical diversity after just one month. Again, however, all these studies described gains made by SA students who went abroad intending to make language gains and who received additional language instruction.

Language gains are often measured by tracing changes in lexical or syntactic complexity, accuracy, or fluency. There are quite a few approaches to measuring these CALF indicators, and to a degree all are conceptually or methodologically contested (Housen \& Kuiken, 2009). Consequently, supplementing CALF outcomes with other data such as test scores and selfassessment data could add robustness to the findings. Nevertheless, in spite of criticism and words of caution, CALF indicators remain important in SLA research because they allow for cross-study comparability (Pallotti, 2009). The CALF indicators used here to measure writing gains are modeled after those used in the Melbourne studies, while indicators for speaking gains were adopted from analogous SA research described in the analysis.

\subsection{Understanding language gains through a social lens}

Understanding the influences that lead to language gains is quite different from measuring them. The Melbourne studies used post-data collection questionnaires and interviews to illuminate their results and found that the participants had received few writing assignments with little feedback on their writing. They had used English frequently to communicate on 
campus and with friends, but this had not measurably impacted their writing. However, these studies didn't include in-depth interviews concerning the social and educational experiences of international students. Few, if any studies have combined quantitative proficiency assessments with the qualitative approach of longitudinal interviews.

Endeavoring to unite these research traditions, The Douglas Fir Group (DFG, 2016) proposed a framework to inspire research investigating the contexts in which L2 acquisition takes place. According to the DFG framework, language learning is a social activity shaped by interpersonal contact, sociocultural institutions, and ideology, thus stressing the importance of the social context in language learning. This is not a new idea (Han, 2016): following Firth and Wagner (1997), scholars generally agree that the ways L2 learners find acceptance in diverse social situations impacts their sense of identity, which in turn shapes L2 development (Norton \& Toohey, 2011; Swain \& Deters, 2007). The DFG framework's tri-layered structure and ten language learning claims are, from a research perspective, its most appealing and innovative aspects.

In the DFG framework, ideology fashions contexts that impact both cultural institutions and individual interactions. As such, ideology determines not only the norms of institutions and societies but also the interpersonal interactions within them. Interpersonal interactions, in turn, are determined by institutional conventions, and vice versa. In addition to this three-tier structure, the DFG framework's authors proposed ten essential themes for SLA, three of which directly relate to the current study: "Ideologies permeate all levels" (DFG, 2016, p. 33), "Agency and transformative power are means and goals for language learning” (DFG, 2016, p. 33), and "Language learning is identity work” (DFG, 2016, p. 31).

First, language ideology refers to the collection of ideas and values that speakers of a dominant discourse community hold about language and the hierarchies between languages (De Costa, 2010; Subtirelu, 2014). Ideologies may remain at the level of language beliefs (Spolsky, 2004), but they may also be translated into policy measures (De Costa, 2010; Linton, 2009; Van Splunder, 2015). Ideology affects the norms of institutions, the expectations communities have of L2 learners, the roles they can expect to assume within those institutions, and the ideas they have about themselves (The Douglas Fir Group, 2016). Currently, a monolingual language ideology is dominant in many European nations (Duarte \& Gogolin, 2013), and the US (Linton, 2009), which may put L2 learners at a disadvantage by promoting the idea that some languages are superior to others (Subtirelu, 2014).

Secondly, regarding agency, the DFG states: "the degree of influence L2 learners can exert in shaping their identities is not equal across contexts" (DFG, 2016, p. 33). Indeed, as research into academic socialization shows, gaining access to the L1 community is challenging for international students (Amuzie \& Winke, 2009; Ranta \& Meckelborg, 2013). Cultural, didactic, linguistic, or social differences may create a sense of distance between L1 and L2 students which can lead to loneliness, alienation, and active or passive exclusion (Gu \& Maley, 2008). The former implies that people are purposefully denied access to a community, while the latter lacks deliberate strategy but may yield similar results (Sen, 2000). Psychology research also supports the importance that the DFG framework assigns to social belonging; the lack of it may result in withdrawal, loneliness, sadness, or shame (Buckley, Winkel, \& Leary, 2004). For international L2 students, this may translate into an unwillingness to participate in class (Morita, 2004) or to interact with L1 students (Kormos, Csizér, \& Iwaniec, 2014).

Thirdly, identity theory posits that identities shape and are shaped by the social structures and the communities in which we live (Norton \& Toohey, 2011). Social groups are gated, and socialization into a new context may be an unsettling experience that requires identity reconstruction as people adjust to new rules and norms (Kinginger, 2010; Norton \& Toohey, 2011; Pellegrino Aveni, 2005). Research among international and study abroad students has found that a new academic environment can destabilize one's self-image (Kinginger, 2010) or lead them to affirm their own cultural identity in opposition to that of the host culture when it appears impenetrable (Gu \& Maley, 2008). Logically, when a smooth transition into the academic L1 community is disrupted, meaningful interaction between L1 and L2 students will be obstructed, which may negatively affect the acquisition of the target language (Amuzie \& Winke, 2009; Ranta \& Meckelborg, 2013). In what follows, we will introduce the research context of this study, and examine language gains made by international students in that context.

\section{Research context}

Research into the language learning processes of international students in higher education has thus far focused on gains in widely taught languages, such as English (Knoch et al., 2015), Spanish (Huensch \& Tracy-Ventura, 2017), or French (Kinginger, 2008). In contrast, this study was conducted in Flanders, the northern part of Belgium where Dutch is the official language. In line with current European trends, the government position towards migration is rather strict (Reynebeau, 2017) and the general attitude of the people towards migrants can be distant: A recent study showed that it typically takes considerable time before migrants feel socially accepted in the Flemish community (ILIV, 2015).

After nearly two centuries of language-related political turmoil, the political language ideology of territorial monolingualism (Blommaert, 2011) has become pervasive in Flemish education too. Many primary and secondary schools use a strict Dutch-only policy (Agirdag, 2010) and higher education has to abide by a language quota: $94 \%$ of all bachelor's programs and 65\% of all master's programs must be taught solely in Dutch. As such, international students who want to attend a Flemish university commonly encounter Dutch as a medium of instruction, along with large, ex cathedra (one-way teacher-fronted) courses that often exceed five hundred students and offer few opportunities for interaction.

In order to ensure that L2 students are able to meet university's linguistic demands, minimum admission requirements have been set at the B2 level of the Common European Framework of Reference for Languages (Council of Europe, 2001). Policy makers realize that B2 learners may not be as proficient as their L1 peers but assume that students will increase their 
proficiency naturally while attending Dutch-medium classes (Deygers et al., 2017). This study contributes to research and addresses matters of real-world policy by questioning that assumption.

\section{Research questions}

This paper reports on spoken and written language gains in Dutch made by international L2 students and sheds light on how the wider educational and social context of the learners might explain these gains. The first research question considers quantitatively gains made by international L2 students during their first year at a Flemish university:

RQ1. Which spoken or written Dutch language gains can be established among the L2 participants, after 8 months at university?

The second research question consists of two parts and analyzes the experiences of the participants at the institutional (RQ2 ${ }_{\mathrm{a}}$ ) and the interpersonal (RQ2 ${ }_{\mathrm{b}}$ ) level to inform our understanding of RQ1:

RQ2 2 . How might university educational practices affect the language learning opportunities of international L2 students?

RQ2 . How might interactions with L1 students affect the language learning opportunities of international L2 students?

\section{Material and methods}

\subsection{Participants}

This study focuses on the language gains made by 20 international L2 students in Flanders. Participants were selected from a pool of 138 students who took part in an earlier project investigating the validity of two university entrance tests (Deygers et al., 2017; Deygers, 2018; Deygers, Van Gorp, \& Demeester, 2018). Of the 138 candidates in that study, 68 achieved a score that allowed them to enroll. Since this study focused on international L2 students attending Dutch-medium university programs, students registering for university college or English-medium programs were excluded. This left 32 possible participants, 20 of whom agreed to participate.

The median participant age was 24 overall, 23 for the ten bachelor students $(\min =19$, $\max =32$ ), and 24 for the ten master students $(\min =19, \max =44)$. Table 1 shows other demographic trends in this predominantly female research population. Most participants were enrolled in one of the three largest universities in Flanders: University of Leuven, Ghent University, and University of Antwerp. At the end of the year, eight participants had passed more than half of their course, and eight had not, which is consistent with the typical success rate of international students in Flanders (Glorieux, Laurijssen, \& Sobczyk, 2015). During the year, four participants dropped out.

\subsection{Data collection and analysis: RQ 1}

This study relies on a sequential explanatory design (Fig. 1), in which longitudinal qualitative data serves to interpret quantitatively measured language gains (Creswell, 2014).

All participants took the STRT test (acronym for Educatief Startbekwaam, or "Educational Start") in summer 2014, started university in September, and were retested on the same STRT tasks again eight months later. The largest international test of Dutch, STRT is a task-based, integrated-skill test at the B2 level and is accepted for admission purposes at all Flemish universities. The written STRT section contains summary tasks based on short lectures and texts and argumentation tasks based on reading and listening samples. The oral component includes a presentation and an argumentation task.

The retest consisted of a selection of two tasks taken from the STRT test the respondents had taken prior to registration. These tasks were chosen according to a multiple linear regression analysis. Using data from the previous STRT administration

Table 1

Population demographics $(\mathrm{N}=20)$.

\begin{tabular}{|c|c|c|}
\hline \multirow[t]{2}{*}{ Gender } & Female & 17 \\
\hline & Male & 3 \\
\hline \multirow[t]{4}{*}{ L1 } & French & 5 \\
\hline & Spanish & 4 \\
\hline & Ukrainian & 2 \\
\hline & Other & 9 \\
\hline \multirow[t]{2}{*}{ Program } & Bachelor & 10 \\
\hline & Master & 10 \\
\hline \multirow[t]{5}{*}{ Department } & Economics & 4 \\
\hline & Law & 4 \\
\hline & Engineering & 2 \\
\hline & Psychology & 2 \\
\hline & Other & 8 \\
\hline \multirow[t]{3}{*}{ Study success } & $\geq 50 \%$ & 8 \\
\hline & $<50 \%$ & 8 \\
\hline & Drop-out & 4 \\
\hline
\end{tabular}




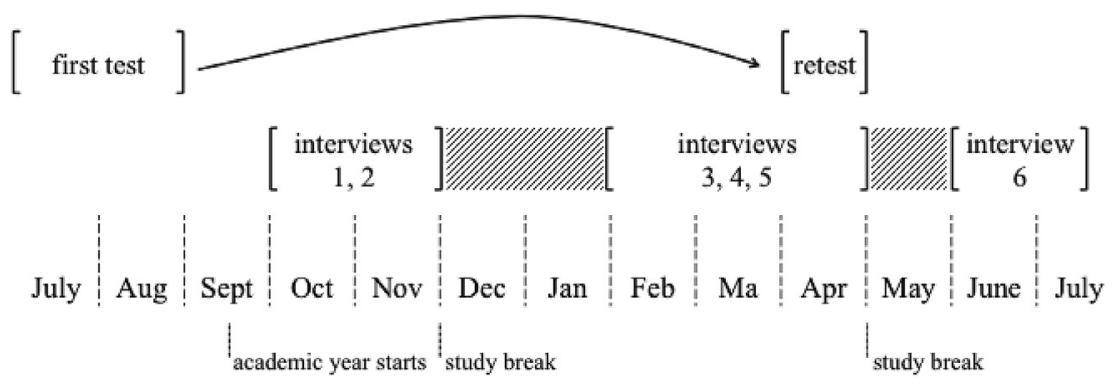

Fig. 1. Data collection design (2014-15).

$(N=913)$, this analysis showed that the oral presentation task $(\beta=0.52)$ and the writing-from-listening summary task $(\beta=0.57)$ explained most of the score variance $\left(R_{a d j}^{2}=0.908, p<.000\right)$. In the first task, students listened to a well-structured 9 -min lecture about industrialization twice and wrote a summary in $30 \mathrm{~min}$. For the presentation task, candidates read a 300word article in $10 \mathrm{~min}$ and then delivered a short presentation using a handout showing seven PowerPoint slides.

Additionally, in an interview conducted one month before the retest, the participants $(n=16)$ were asked to self-assess whether their speaking, writing, listening, or reading skills had become much better, better, remained stable, or was worse.

A repeated-measure within-subject methodology was used to measure language gains (Kinginger, 2008; Knoch et al., 2014, 2015; Storch, 2009). For triangulation, three different indicators of language gains were employed: STRT scores, CALF measures, and the participants' self-assessment.

The STRT rating scales included both content accuracy criteria and linguistic criteria (e.g., grammar, vocabulary), which were then scored using four-band CEFR-based descriptors. This analysis focused on productive gains, but indirect evidence regarding receptive gains was available via the content scores. All performances were anonymously double-rated by independent, trained STRT raters. A Rasch analysis of the performances $(N=116)$ that these raters had scored in previous assignments showed acceptable levels of inter-rater reliability (inter-rater agreement $=83 \% ; X^{2}(4)=3.1, p=.55$ ).

The performances on these tasks from university admission language tests were then analyzed according to CALF measures. The measures used in this study (Table 2) were adopted from studies of comparable contexts or populations.

Two measures were used to determine gains on oral and written syntactic complexity: clauses per T-unit (i.e., the main clause plus all subordinate clauses, Serrano et al., 2012) and words per clause (oral: words per T-unit, Leonard \& Shea, 2017).

Oral and written lexical complexity were measured by average word length, by the proportion of academic words (a defined by the InLaTo corpus for Dutch, $>1,000,000$ words), and by Guiraud's index - a stable indicator of lexical richness (Treffers-Daller, Parslow, \& Williams, 2016).

Written accuracy was measured by the proportion of error-free T-units and the proportion of errors per T-unit (Iwashita, Brown, McNamara, \& O'Hagan, 2008). For spoken accuracy the proportion of errors per 100 words was used, in addition to the proportion of errors per T-unit.

For written fluency, the number of words per T-unit, the total number of words, and the total number of T-units were used. Oral fluency was measured by the number of words and T-units per minute, the number of syllables per minute (i.e., pruned to exclude repetitions and false starts), and speech rate (Huensch \& Tracy-Ventura, 2017). This focused on speed fluency ("rate and density of delivery", Housen \& Kuiken, 2009, p. 463), rather than on breakdown or repair fluency since speed fluency gains have frequently been observed after relatively short SA intervals (Huensch \& Tracy-Ventura, 2017; Serrano et al., 2012). If fluency gains occurred, it would be reasonable to assume that speed fluency indicators would show this.

Table 2

CALF indicators used.

\begin{tabular}{|c|c|c|}
\hline & Written production & Oral production \\
\hline \multirow[t]{2}{*}{ Syntactic complexity } & Clauses/T-unit $^{12}$ & Clauses/T-unit ${ }^{1}$ \\
\hline & Words/clause ${ }^{2}$ & Words/T-unit ${ }^{3}$ \\
\hline \multirow{3}{*}{ Lexical complexity } & Average word length ${ }^{2}$ & Average word length \\
\hline & Proportion academic words ${ }^{2}$ & Proportion academic words \\
\hline & Guiraud's Index ${ }^{1}$ & Guiraud's Index ${ }^{13}$ \\
\hline \multirow[t]{2}{*}{ Accuracy } & Errors/T-Unit ${ }^{12}$ & Errors/T-unit ${ }^{1}$ \\
\hline & Error-free T-units $^{2}$ & Errors/100 words ${ }^{3}$ \\
\hline \multirow[t]{2}{*}{ Fluency } & Words/T-unit ${ }^{12}$ & Syllables $/ \mathrm{min}^{1}$ \\
\hline & Number of words ${ }^{2}$ & Speech rate ${ }^{13}$ \\
\hline
\end{tabular}

Number of T-units ${ }^{2}$.

${ }^{1}$ Llanes et al., 2012; Serrano et al., 2012.

2 Knoch et al., 2015.

${ }^{3}$ Leonard \& Shea, 2017. 
The author coded all STRT performances for CALF indicators, and half of the performances were randomly selected for double coding by a trained research assistant. The level of agreement between the two coders was satisfactory for the oral $(n=10)$ and the written $(n=10)$ performances, for T-units (Oral: exact agreement 90\%; $K_{w} 0.815, p<.001 /$ Written: exact agreement 98\%; $K_{w} 0.936, p<.001$ ), clauses (Oral: exact agreement 95\%; $K_{w} 0.91, p<.001 /$ Written: exact agreement $91 \%$; $K_{w}$ $0.831, p<.001$ ), and error-free T-units (Oral: exact agreement $70 \% ; K_{w} 0.877, p<.001 /$ Written: exact agreement $82 \%$; $K_{w}$ $0.830, p<.001)$. Instances of coder disagreement were individually verified and resolved.

All quantitative analyses were conducted using $R$ (version 3.3.2), coin, effsize and irr packages. Wilcoxon's Signed Rank Test and effect sizes $d$ were used to determine the significance and magnitude of CALF and score gains. In line with Plonsky and Oswald's (2014) recommendation for within-group comparisons, we distinguished between small $(d=0.60)$, medium $(d=1.00)$, and large $(d=1.40)$ effect sizes. Effect sizes below $d=0.3$ were considered negligible.

\subsection{Data collection and analysis: $R Q 2$}

Throughout the academic year, the participants also took part in monthly semi-structured interviews (median duration $=44 \mathrm{~min}, \operatorname{Min}=24^{\prime}$, Max $=97^{\prime}$ ), except during the study-intensive months of December, January and May. Each monthly interview had a different focus, paralleling the structure of the academic year. The first interview emphasized the admission procedure and the first weeks at the university. Subsequent interviews dealt with in-class experiences (November), exams (February), L1 peers (March), language gains (April), and reflecting on the year (June). Issues regarding the participants' social life, academic experiences and language use were always discussed. When participants dropped out, an exit interview was scheduled or, if this was impossible (e.g., when participants had been ordered to leave the country), the interview was conducted via e-mail exchange. The author also took field notes in November when observing in-class interactions between participants and their professors or classmates.

All interviews were audio recorded and transcribed, and three randomly selected interviews were fully transcribed twice to verify transcription accuracy. The overlap between the transcription pairs was checked using the Jaccard index $J$ and the Sørensen-Dice index QS, two indices commonly used in information retrieval methodology (Manning, Raghavan, \& Schütze, 2008). The results indicate an acceptable degree of overlap in the interviewer $(J=0.9 ; Q S=0.95)$ and interviewee transcripts $(J=0.77 ; Q S=0.87)$. The transcripts were then coded and analyzed in NVivo 11 . To answer our research questions, an a priori coding scheme with 5 fixed coding categories ("Background variables", "Academic work", "Language use”, "Language tests", and "Identity") was set up (Miles, Huberman, \& Saldaña, 2013), but the primary researcher was free to add an open, inductive layer of coding whenever striking themes emerged. All transcripts from November, a randomly selected month, were recoded by a trained research assistant, which verified $92 \%$ inter-coder agreement, and $97 \%$ intra-coder consistency of the primary researcher. All participants were assigned a pseudonym to protect their identity.

\section{Results}

\subsection{Linguistic gains after 8 months at university}

Between the first STRT administration and the second eight months later, the scores on STRT tasks did not undergo any significant changes, and most effect sizes were small. The scores on the oral task (Table 3) marginally decreased over time, but no demonstrable change took place (overall $d=0.11$; linguistic $d=0.01$ ). The median content scores rose slightly, and an analysis of the score gains on linguistic criteria revealed small effect sizes (pronunciation $d=.42$, vocabulary $d=0.39$,

Table 3

Speaking gains.

\begin{tabular}{|c|c|c|c|c|c|c|}
\hline & Test $M d$ & Retest $M d$ & $W$ & $p$ & $d$ & $(90 \% \mathrm{CI})$ \\
\hline \multicolumn{7}{|l|}{ Test scores } \\
\hline Linguistic $(\max =24)$ & 18 & 17 & 40.5 & .999 & .01 & $(-0.88,0.87)$ \\
\hline Content $(\max =15)$ & 12 & 11 & 48.5 & .505 & .15 & $(-0.72,1.03)$ \\
\hline \multicolumn{7}{|l|}{ Syntactic complexity } \\
\hline Clauses/T-unit & 0.41 & 0.38 & 49 & .479 & .28 & $(-0.59,1.16)$ \\
\hline Words/T-unit & 11.6 & 11.8 & 40 & .998 & -.04 & $(-0.91,0.83)$ \\
\hline \multicolumn{7}{|l|}{ Lexical complexity } \\
\hline Average word length & 1.51 & 1.51 & 39.5 & .964 & -.14 & $(-1.01,0.73)$ \\
\hline Academic word list & 0.06 & 0.06 & 31 & .414 & -.52 & $(-1.41,0.36)$ \\
\hline Lexical richness & 38 & 37 & 41.5 & .964 & -.15 & $(-1.02,0.72)$ \\
\hline \multicolumn{7}{|l|}{ Accuracy } \\
\hline Errors/T-unit & 0.86 & 0.86 & 46 & .658 & .17 & $(-0.70,1.04)$ \\
\hline Errors/100 words & 0.29 & 0.44 & 27.5 & .269 & -.4 & $(-.69,1.06)$ \\
\hline \multicolumn{7}{|l|}{ Fluency } \\
\hline Syllables/min & 104.5 & 133.5 & 22 & .113 & -.7 & $(-1.59,0.21)$ \\
\hline Speech rate & 1.16 & 1.46 & 27 & .258 & -.63 & $(-0.25,1.54)$ \\
\hline
\end{tabular}


grammar $d=0.37$, initiative $d=-0.17$, cohesion $d=-0.11$, fluency $d=-0.08$ ). On the writing task (Table 4 ), the median scores for linguistic and content criteria increased (linguistic $d=-0.48$, content $d=-0.34$ ), but since the median score on the first test already neared the maximum, a ceiling effect likely curbed measurable growth. Effect sizes for the separate linguistic criteria varied from small (spelling $d=-0.37$, vocabulary $d=-0.21$, grammar $d=-0.11$ ) to medium (cohesion $d=-0.98$ ). The confidence interval for every test criterion included zero, meaning that any differences between test and retest scores were not significant.

In the speaking tasks (Table 3), the largest effects were found for fluency indicators: the number of syllables per minute $(d=-0.7)$ and speech rate $(d=-0.63)$. Other indicators yielded small to negligible effect sizes. No medium or large oral gains were found after eight months of university study in Dutch. Using AS-units instead of T-units - as has been recommended for oral performances (Foster, Tonkyn, \& Wigglesworth, 2000) - yielded comparable results (e.g., Clauses/AS unit: $W=50$, $p=.436, d=0.27,90 \% \mathrm{CI}=-0.79-1.33$ /Errors/AS unit: $W=49, p=.999, d=0.07,90 \% \mathrm{CI}=-0.9-1.14)$.

The largest CALF writing gains (Table 4) were found for one indicator of fluency: the number of words written in a 30-min timeframe $(d=-0.96)$, which is the only indicator from any of the tasks in which the confidence interval does not include zero (i.e., a significant effect at the 0.1 confidence level). The gains are not consistent across all written fluency measures, however (e.g., number of words per T-unit $d=-0.01$ ), and all other writing gains were small or negligible.

There are no immediate reasons to assume that the participants underperformed during the retest. They were motivated to show language gains, and participated voluntarily with the intention to find out whether their Dutch had improved. After the oral task, four participants spontaneously stated that they had been more nervous for the retest than for the first test.

These quantitative results largely paralleled the participants' perceived gains (Table 5). Roughly two thirds believed they had made no gains in speaking or writing, but more participants described perceived listening and reading gains. Importantly, there were no perceived or measurable differences between the language gains of first year students and master students.

\subsection{Institutional variables}

Because of the predominantly ex cathedra teaching style and large class sizes in the research context, interaction between the participants and their professors was rare. In October, nineteen participants reported only limited contact with teaching staff, while nine participants explicitly mentioned feeling uneasy in class about their L2-ness. Clara discussed one such episode:

The professor asked me a question. My face turned red and I said, 'Sorry I speak French, I didn't understand everything.' She looked at me without a smile, then she looked at the auditorium and said 'Madam speaks French.'

(Clara, November)

Table 4

Writing gains.

\begin{tabular}{|c|c|c|c|c|c|c|}
\hline & Test $M d$ & Retest $M d$ & $W$ & $p$ & $d$ & $(90 \% \mathrm{CI})$ \\
\hline \multicolumn{7}{|l|}{ STRT scores } \\
\hline Linguistic $(\max =16)$ & 10 & 11 & 34 & .235 & -.48 & $(-1.31,0.35)$ \\
\hline Content $(\max =8)$ & 7.5 & 8 & 36.5 & .311 & -.34 & $(-1.31,0.35)$ \\
\hline \multicolumn{7}{|l|}{ Syntactic complexity } \\
\hline Clauses/T-unit ${ }^{12}$ & 0.28 & 0.25 & 58.5 & .544 & .41 & $(-0.41,1.24)$ \\
\hline Words/clause $^{2}$ & 9 & 8.7 & 50 & .999 & .07 & $(-0.75,0.89)$ \\
\hline \multicolumn{7}{|l|}{ Lexical complexity } \\
\hline Average word length & 1.92 & 1.86 & 66.5 & .225 & .37 & $(-0.49,0.34)$ \\
\hline Prop academic words & 0.12 & 0.11 & 61 & .419 & .41 & $(-0.42,1.23)$ \\
\hline Guiraud's Index & 56.5 & 57.5 & 52.5 & .878 & .36 & $(-0.46,1.19)$ \\
\hline \multicolumn{7}{|l|}{ Accuracy } \\
\hline Errors/T-Unit & 0.94 & 0.95 & 52 & .910 & -.05 & $(-0.87,0.77)$ \\
\hline Error-free T-units & 0.3 & 0.32 & 56 & .677 & .24 & $(-0.58,1.06)$ \\
\hline \multicolumn{7}{|l|}{ Fluency } \\
\hline Words/T-unit & 11.5 & 11.1 & 52 & .911 & .01 & $(-0.81,0.83)$ \\
\hline Number of words & 207 & 240 & 26 & .075 & -.96 & $(-1.83,-0.09)$ \\
\hline Number of T-units & 18 & 22 & 31.5 & .172 & -.52 & $(-1.35,0.31)$ \\
\hline
\end{tabular}

Table 5

Participants' perceived gains.

\begin{tabular}{lllll}
\hline & Much better & Better & Stable & Undecided \\
\hline Speaking & 2 & 3 & 7 & 3 \\
Writing & 3 & 1 & 7 & 4 \\
Listening & 3 & 5 & 7 & 1 \\
Reading & 5 & 6 & 4 & 1 \\
\hline
\end{tabular}


Although only four participants reported intimidating classroom experiences instigated by professors, all participants mentioned four primary obstacles to their inclusion in the university: group size, non-interactive teaching, linguistic unpreparedness, and a perceived lack of attention to international L2 students. As a result, most participants felt ignored or invisible.

After their first class, all participants mentioned the lack of interaction as a striking characteristic of the teacher-fronted classes, though it was not necessarily seen as a disadvantage. Most participants felt that although ex cathedra teaching was monotonous, it shielded them from the active participation which many dreaded. In October, fifteen participants expressed language-related fears about answering questions in class. By November, four of the eighteen remaining participants had not yet spoken any Dutch, five had rarely done so, and five were afraid to speak. By that point, only four participants reported having spoken Dutch often. Even in February, students reported attitudes such has Hoang's: "I don't dare to speak to [my classmates] because they talk so quickly, and I don't understand [...] I feel such shame when I need to speak." In the final exit interviews, six of the remaining sixteen participants reported that these interviews had been the only occasions during the year when they had spoken Dutch.

The participants also had few opportunities to practice writing in Dutch. All had taken Dutch-medium written examinations, but none had received any linguistic feedback. Only four participants were given a writing assignment during the year, but two received permission to write in English. The other two participants wrote a section of a group assignment, and in those cases the L1 students corrected language errors before the task was submitted without involving the participants.

Another reason participants struggled as L2 learners was due to an inability to fully understand their professors, since not all professors used the standard variety of Dutch. Consequently, all participants expressed difficulty comprehending the accents used in class, and three reported not having understood a single thing during their initial classes. Understanding classroom discourse appeared to be a prerequisite for developing a sense of belonging. The five participants who did not feel at home in class at any point during the year all mentioned problems understanding professors' speech, which they described as alienating or humiliating:

Once, we had a guest lecture in English and the lecturer asked many questions and I could answer [...] I knew everything! And for the first time I felt at home. Normally I am just confused all the time: "Why am I here? I don't understand anything."

(Oksana, January)

\subsection{Interaction between $L 1$ and $L 2$ students}

Throughout the academic year, nineteen of twenty participants reported loneliness, exclusion and alienation resulting from interactions with other students. At least seven experienced active exclusion by L1 students, two reported being purposefully misinformed about study-related matters, and one was repeatedly given false instructions about group work meeting times and locations. Others sought contact with L1 classmates, but were rejected: "Somebody told me 'we already have a group of friends, why add a francophone?"' (Chloé, October). However, most exclusion was passive. Gabriela's anecdote is representative of the experiences of many participants:

There's two girls: one here [points right] and one here [points left]. I talk to these girls sometimes. So one girl asks the other "do you want to get a coffee"? And I'm right in the middle! And I wonder if I can go too, but then I think "I'm in the middle and they don't ask me".

(Gabriela, March)

Not all participants were socially isolated, but befriending Flemish classmates occurred rarely. Outside of class, most participants met with other international students and used English or their L1 as a lingua franca. At home (Table 6), one participant used only Dutch and two used Dutch in combination with their L1, but seventeen did not use Dutch at all. Those who did either lived with a Flemish partner (3) or shared a house with Flemish students (1).

By April, only two participants had made friends with L1 classmates. The most common reason participants gave for failing to gain access to the L1 community was "being ignored." This, in turn impacted the participants' self-perception. After one month at university, 15 participants perceived themselves as stupid, incompetent or unlikeable to their L1 classmates, and 18

Table 6

Housing and language used at home.

\begin{tabular}{|c|c|c|c|c|c|c|c|}
\hline \multirow[t]{2}{*}{ Housing } & \multirow[t]{2}{*}{$n$} & \multicolumn{6}{|c|}{ Language used at home } \\
\hline & & $\mathrm{N} / \mathrm{A}$ & L1 & Eng & $\mathrm{L} 1+$ Dutch & L1+Eng & Dutch \\
\hline Alone & 7 & 7 & & & & & \\
\hline Shared: boyfriend & 3 & & 1 & 2 & & & \\
\hline Shared: family & 2 & & & & 2 & & \\
\hline Shared: relatives & 2 & & 2 & & & & \\
\hline Shared: students & 6 & & 1 & 2 & & 2 & 1 \\
\hline
\end{tabular}


reported that their self-perception had been negatively impacted by attending a Flemish university. Most doubted their own abilities at some point. For example, Oksana shared:

Every day I was crying. And then you think "ok don't cry just go on”. And then I go on and see that it doesn't work and I get sad again and then you think "ok this is not the way [...] the professor will think that I am stupid, that I have no talent, not enough knowledge."

(Oksana, July)

Seven months into the academic year, nine out of sixteen participants presumed that their L1 classmates were indifferent to or unaware of them. Four others thought that L1 students considered them stupid, strange, or lazy. The sense that members of the L1 community considered them inferior constituted another obstacle to their integration when participants faced linguistic or sociocultural differences. By the end of the second semester, most participants had accepted their quasisegregation from the L1 student community. Some responded by keeping their distance or by projecting feelings of superiority based on perceived differences in maturity or financial dependence.

In Flanders you often see mummy coming along, like "oh you need stuff for university? I will come to the bookstore and pull out my credit card" [...] That difference feels like a wall to me. I have gone through so much to become independent and students here just aren't.

(Hoang, March)

Importantly, no participants experienced only interpersonal or only institutional difficulties: in-class experiences impacted interpersonal relationships, and vice versa. This is perhaps most clear from the testimonies of participants who left prematurely; they dropped out due to a combination of interpersonal or institutional factors. Anastasia's exit interview shows how problems on the interpersonal level aggravated frustrations with perceived institutional shortcomings:

I don't like the university, the weird way of teaching and of dealing with students. [...] After the first month it was clear that I would not be happy here. I went to class and nobody spoke to me. When I asked a question, people replied politely, but that was it. And when I went to the student support service they didn't offer any help.

(Anastasia, February)

When contacted two years after the original data collection, eight participants replied to a follow-up e-mail enquiring about how they had been doing. They all agreed that listening and reading in non-dialectal Dutch posed next to no problems anymore, but they had not perceived any progress in speaking or writing. Four had graduated and had found a job, two were still at university (one had passed every exam, one was still in taking freshman courses), and two had decided to switch to an English-medium program. For eight participants, life at university had become easier after the first year.

\section{Discussion}

\subsection{Linguistic gains}

This study offers no evidence to support the claim that the participants had made substantial demonstrable productive language gains after eight months of university study. Three different sources of evidence were investigated: test scores, CALF indicators, and perceived gains. First, an analysis of the language test scores showed neither substantial score gains nor losses, although positive and negative changes did occur, resulting in small effect sizes and non-significant fluctuations. Furthermore, when considering the CALF indicators, only one medium-sized effect was found: participants wrote substantially more words within $30 \mathrm{~min}$. Overall, the largest effects were found for fluency, and the smallest for syntactic complexity and accuracy. Thus, heeding Pallotti's (2009) advice about not attaching too much importance to single CALF indicators that contradict a general trend, it seems safe to conclude that the overall data offers no convincing evidence to suggest that participants made productive language gains during their first academic year. Lastly, two-thirds of the participants agreed in a self-assessment that their productive skills had either remained stable or had deteriorated. The same self-assessment showed that the hours spent listening to academic lectures and reading course material had led to improved receptive skills. The overall consensus was that reading and listening had become easier.

The small participant size belies wide generalization, but the credibility of these findings is consistent with similar outcomes of earlier research concerning increases in writing fluency among international L2 students (see Knoch et al., 2015 , 2014). Furthermore, the gains for oral fluency as measured by a monologic speaking task were larger than those for accuracy, which parallels the findings of Tavakoli (2018) in particular, and also several other recent studies of SA learning (Huensch \& Tracy-Ventura, 2017; Leonard \& Shea, 2017; Serrano et al., 2012), even though the gains for international students and SA students cannot truly be equated.

\subsection{Contextual variables and language learning opportunities}

Interpersonal and institutional barriers could have contributed to the limited productive gains made by these participants in a number of ways that are consistent with prior research. The data presented here show that very few participants frequently used Dutch outside of the academic context. For a variety of interconnected reasons, including perceived linguistic 
inferiority and lack of access to the L1 community, most participants were not able to engage in meaningful interaction in Dutch, which is essential for making language gains. When the dominant language ideology is monolingual, as is the case in Flanders, negative attitudes towards L2 learners may arise, and these attitudes, which have been documented in primary (Jordens, 2016) and secondary schools (Agirdag, 2010) can, according to this study, persist at university as well.

Furthermore, the various obstacles to interaction that emerged as themes in the interviews led students to question their self-image, just as previous research has found (See Kormos et al., 2014; Kinginger, 2008, 2010). First, participants did not feel that the university attended to their linguistic needs. All participants experienced problems understanding lectures, were unprepared for professors' accentual variations, and not given linguistic feedback on writing assignments. Socially, participants generally felt invisible in large auditoriums, but when their presence was acknowledged, they commonly responded with feelings of anxiety or fear of ridicule. Similar issues were experienced by participants in prior studies by Ranta and Meckelborg (2013) and Knoch et al., 2014, 2015).

Secondly, this study did not find examples of non-hierarchical collaboration between L1 and L2 students. L1 peers asserted power over participants by not involving them in revisions or purposefully misinforming them about meetings. Classmates excluded participants actively (on the basis of geographical ties or pre-existing friendships) and passively (as a result of cultural, demographic, or linguistic differences), but regardless of type, the result was the same: very few participants gained access to the L1 community. Thus, this outcome backs up international findings (Gu \& Maley, 2008; Sen, 2000) and Flemish research (ILIV, 2015).

Another obstacle, perceived linguistic inferiority, was evident from descriptions of the participants' interactions with L1 students. Van Splunder (2015) writes that the language norm in Flanders is not simply correct Dutch, but highly idiomatic native-like Dutch. His assertion that there is little tolerance towards language learners who do not attain that norm may explain the fear of ridicule that withheld many participants from speaking. In line with Morita (2004), it could be argued that the inability to attain the implicit linguistic norms reduced the international L2 students' willingness to participate in class.

The data collected in the current study also fuels the hypothesis that segregation from L1 students may lead to self-doubt among international students (Buckley et al., 2004). Over time, these feelings motivated participants to distance themselves from the L1 students. The most prevalent effect of perceived inferiority, however, was identity reconstruction: participants in this study adjusted their self-perception downwards to align with their perceived new status, as was observed in Kinginger (2010) and Pellegrino Aveni (2005).

Overall, the data in this study shows an interesting cycle, which illustrates the three levels in the DFG framework. The participants enrolled at university with a B2 level, and found that their language proficiency level was below the real-world linguistic requirements of university (Deygers et al., 2017). As a consequence, feelings of linguistic inferiority ensued, reducing L2 students' willingness to interact, and possibly hampering gains. The institutional context (the meso level in the DFG framework), typified by large class sizes and impacted by larger ideological forces (the macro level in the DFG framework), of monolingualism, created a setting that L2 students perceive as unwelcoming. The institutional environment did not stimulate cooperation on an interpersonal level (the micro level in the DFG framework), between L1 and L2 students, and student groups who did not interact during class also refrained from doing so outside of class. Consequently, receiving spoken and written Dutch input without substantial productive demands did not result in demonstrable productive language skill gains. Thus, this study, offers little or no support to the assumption that rich input alone will yield language gains (e.g. Gass, 2003; Krashen, 1985, DFG, 2016), and more support to the idea that language learning is conditional upon sufficient opportunities for meaningful interaction in a real-world setting (DFG, 2016; Ellis, 2003; Swain, 2000). Methodologically, this study also shows that the DFG's three-tier structure can be used as a framework for analysing real-world language learning processes.

\section{Conclusion and implications}

By connecting ideological, institutional and interpersonal variables to language gains, this article offers a more complete picture of the continuation of language learning for L2 international students after they enter tertiary education. The results substantiate previous findings, while adding novel insights regarding speaking gains. Certain trends which have been observed at English-medium universities (limited gains, limited access to the L1 community) have been corroborated, while outcomes reported in other earlier studies were not confirmed, namely that participants did not use the instruction-medium language outside of class, preferring to communicate in English or their L1.

The study reported on in this paper has a few limitations. First, an eight-month time period could be considered rather brief to measure language gains. On the other hand, gains have been measured in SA studies that covered substantially shorter periods - but these studies focused on contexts in which students attended additional language courses. Furthermore, the eight-month period is a meaningful time-span, since it runs from the start of the academic year until the final examinations, at which point policy makers expect international students to have made the necessary language gains (Deygers et al., 2017). Secondly, gains were measured using generic indicators. Possibly, using discipline-specific markers of language development would have yielded other gains. Thirdly, Because of sample size, it would be imprudent to generalize too broadly from this study. Nevertheless, the outcomes do offer a foundation for policy recommendations. First, this study shows that a sudden transition to university, which may be intimidating for any 18-year old, can be a demoralizing experience for an international L2 student. Consequently, in line with previous research (e.g. Kinginger, 2008), it took most participants several months to adapt. It is not inconceivable that participants in this study could have fared better if they had experienced a smoother 
transition. Therefore, initiatives that foster a gradual and guided transition to university could be vital for increasing international students' chances of academic success.

Additionally, universities need to develop clear and transparent support systems. It should be clear for international students from day one what accommodations are available to them. Thirdly, this study reaffirmed that international students may not be immediately ready for the linguistic demands of university (Deygers et al., 2017; Field, 2011). It has also confirmed that L2 students will not necessarily make language gains by virtue of attending Dutch-medium classes. With Byrnes, Maxim, and Norris (2010), universities could consider establishing clear L2 attainment targets in addition to entry requirements. If a university expects international L2 students with insufficient language skills to understand lectures, that university has a responsibility to provide opportunities for international students to develop their $\mathrm{L} 2$ to the level necessary for success.

Additional research is needed into the language learning successes of L2 students after entering the university. Corroborative studies in various L2 contexts would enhance our understanding of international students' success that could then be used to improve study experiences globally. Lastly, even though this paper focused on international L2 students, the author does not suggest that L1 users are free from problems related to identity, power and exclusion. Contrasting the experience of L1 users and L2 learners at university would be a valuable topic for further research.

\section{Acknowledgements}

I would like to express my deepest gratitude and respect to all twenty participants for their openness and candor, even when times were rough. I would also like to thank Prof. Lourdes Ortega for her inspiring ideas, dr. Koen Van Gorp, Prof. Kris Van den Branden and Prof. Jordi Casteleyn for their suggestions along the way, and dr. Thomas Demeester for the assistance with text similarity indices. Lastly, a word of thanks to the editorial team at System and to the reviewers for a smooth and constructive review process.

This work was funded by the Research Foundation Flanders, FWO Vlaanderen, under Grant number G078113N.

\section{Appendix A. Supplementary data}

Supplementary data related to this article can be found at https://doi.org/10.1016/j.system.2018.05.012.

\section{References}

Agirdag, O. (2010). Exploring bilingualism in a monolingual school system: Insights from Turkish and native students from belgian schools. British Journal of Sociology of Education, 31(3), 307-321.

Amuzie, G., \& Winke, P. (2009). Changes in language learning beliefs as a result of study abroad. System, 37(3), 366-379.

Blommaert, J. (2011). The long language-ideological debate in Belgium. Journal of Multicultural Discourses, 6(3), 241-256.

Briggs, J. (2015). Out-of-class language contact and vocabulary gain in a study abroad context. System, 53(Supplement C), $129-140$.

Buckley, K., Winkel, R., \& Leary, M. (2004). Reactions to acceptance and rejection: Effects of level and sequence of relational evaluation. Journal of Experimental Social Psychology, 40(1), 14-28.

Byrnes, H., Maxim, H., \& Norris, J. (2010). Realizing advanced foreign language writing. The Modern Language Journal, $94,1-202$.

Cantwell, B. (2015). Are international students cash cows? Examining the relationship between new international undergraduate enrollments and institutional revenue at public colleges and universities in the US. Journal of International Students, 5(4), $512-525$.

Chirkov, V., Vansteenkiste, M., Tao, R., \& Lynch, M. (2007). The role of self-determined motivation and goals for study abroad in the adaptation of international students. International Journal of Intercultural Relations, 31, 199-222.

Council of Europe. (2001). Common european framework of reference for Languages: Learning, teaching, assessment. Strasbourg: Council of Europe.

Creswell, J. W. (2014). A concise introduction to mixed methods research. Los Angeles: Sage.

De Costa, P. (2010). Language ideologies and standard English language policy in Singapore: Responses of a "designer immigrant" student. Language Policy, 9(3), 217-239.

De Costa, P., Rawal, H., \& Zaykovskaya, I. (2017). Introduction: Methodological diversity and innovation in study abroad research. System, 71, 1-6.

Deygers, B. (2018). University entrance language tests: examining assumed equivalence. In J. Davis, J. Norris, M. Malone, T. McKay, \& Y. Son (Eds.), Useful assessment and evaluation in language education. Washington, D.C.: Georgetown University Press.

Deygers, B., Van den Branden, K., \& Van Gorp, K. (2017). University entrance language tests: A matter of justice. Language Testing (Published online first).

Deygers, B., Van Gorp, K., \& Demeester, T. (2018). The B2 level and the dream of a common standard. Language Assessment Quarterly, 15(1), 44-58.

DFG. (2016). A transdisciplinary framework for SLA in a multilingual world. The Modern Language Journal, 100(S1), 19-47.

Duarte, J., \& Gogolin, I. (2013). In Linguistic superdiversity in urban Areas: Research approaches. Amsterdam ;; Philadelphia: John Benjamins Publishing Company.

Ellis, R. (2003). Task-based language learning and teaching. Oxford: Oxford University Press.

Engle, L., \& Engle, J. (2003). Study abroad levels: Toward a classification of program types. Frontiers: The Interdisciplinary Journal of Study Abroad, 9, 1-20. European Commission. (2015). Erasmus. Facts, figures \& trends. Brussels: European Commission.

Field, J. (2011). Into the mind of the academic listener. Journal of English for Academic Purposes, 10(2), 102-112.

Firth, A., \& Wagner, J. (1997). On discourse, communication, and (some) fundamental concepts in SLA research. The Modern Language Journal, 81(3), $285-300$.

Foster, P., Tonkyn, A., \& Wigglesworth, G. (2000). Measuring spoken language: A unit for all reasons. Applied Linguistics, $21(3), 354-375$.

Gass, S. (2003). Input and interaction. In C. Doughty, \& M. Long (Eds.), Handbook of second language acquisition (pp. 224-250). Oxford: Blackwell.

Glorieux, I., Laurijssen, I., \& Sobczyk, O. (2015). Studiesucces in het eerste jaar hoger onderwijs in Vlaanderen. Een analyse van de impact van kenmerken van studenten en van opleidingen. Leuven: Steunpunt SSL.

Green, T. (2004). Making the grade: Score gains on the IELTS writing test. Cambridge ESOL Research Notes, 16, 9-13.

Gu, Q., \& Maley, A. (2008). Changing places: A study of Chinese students in the UK. Language and Intercultural Communication, 8(4), 224-245.

Han, Z. (2016). A "reimagined SLA" or an expanded SLA?: a rejoinder to the Douglas Fir group (2016). The Modern Language Journal, 100(4), 736-740.

Housen, A., \& Kuiken, F. (2009). Complexity, accuracy, and fluency in second language acquisition. Applied Linguistics, $30(4)$, 461-473.

Huensch, A., \& Tracy-Ventura, N. (2017). L2 utterance fluency development before, during, and after residence abroad: A multidimensional investigation. The Modern Language Journal, 101(2), 275-293. 
ILIV. (2015). Roots!België als thuisland voor andere culturen. Brussels: ILIV.

Iwashita, N., Brown, A., McNamara, T., \& O'Hagan, S. (2008). Assessed levels of second language speaking Proficiency: How distinct? Applied Linguistics, 29(1), 24-49.

Jordens, K. (2016). Turkish is not for learning, Miss. Valorizing linguistic diversity in primary education. Leuven: KU Leuven.

Kinginger, C. (2008). Language learning in study Abroad: Case studies of americans in France. The Modern Language Journal, 92, 1-124.

Kinginger, C. (2010). American students abroad: Negotiation of difference? Language Teaching, 43(2), 216-227.

Knoch, U., Rouhshad, A., Oon, S. P., \& Storch, N. (2015). What happens to ESL students' writing after three years of study at an English medium university? Journal of Second Language Writing, 28, 39-52.

Knoch, U., Rouhshad, A., \& Storch, N. (2014). Does the writing of undergraduate ESL students develop after one year of study in an English-medium university? Assessing Writing, 21, 1-17.

Kormos, J., Csizér, K., \& Iwaniec, J. (2014). A mixed-method study of language-learning motivation and intercultural contact of international students. Journal of Multilingual and Multicultural Development, 35(2), 151-166.

Krashen, S. (1985). The input Hypothesis: Issues and implications. London, New York: Longman.

Leonard, K., \& Shea, C. (2017). L2 speaking development during study Abroad: Fluency, accuracy, complexity, and underlying cognitive factors. The Modern Language Journal, 101(1), 179-193.

Linton, A. (2009). Language politics and policy in the United States: Implications for the immigration debate. International Journal of the Sociology of Language, 2009(199), 9-37.

Llanes, A., Tragant, E., \& Serrano, R. (2012). The role of individual differences in a study abroad experience: The case of Erasmus students. International Journal of Multilingualism, 9(3), 318-342.

Manning, C., Raghavan, P., \& Schütze, H. (2008). Introduction to information retrieval. New York: Cambridge University Press.

Miles, M., Huberman, A. M., \& Saldaña, J. (2013). Qualitative data analysis: A methods sourcebook (3 edition). Thousand Oaks, Califorinia: SAGE Publications, Inc.

Morita, N. (2004). Negotiating participation and identity in second language academic communities. TESOL Quarterly: A Journal for Teachers of English to Speakers of Other Languages and of Standard English as a Second Dialect, 38(4), 573-603.

NAFSA. (2017). Trends in U.S. Study abroad. Retrieved February 6, 2018, from nafsa.org.

Norton, B., \& Toohey, K. (2011). Identity, language learning, and social change. Language Teaching, 44(4), 412-446.

OECD. (2017). Education at a glance 2017: OECD indicators. Paris: OECD Publishing.

Pallotti, G. (2009). CAF: Defining, refining and differentiating constructs. Applied Linguistics, 30(4), 590-601.

Pellegrino Aveni, V. (2005). Study abroad and second language Use: Constructing the self. Cambridge: Cambridge University Press.

Pérez-Vidal, C. (2014). Language acquisition in study abroad and formal instruction contexts. Amsterdam: John Benjamins Publishing Company.

Plonsky, L., \& Oswald, F. (2014). How big is "Big"? Interpreting effect sizes in L2 research. Language Learning, 64(4), 878-912.

Ranta, L., \& Meckelborg, A. (2013). How much exposure to English do international graduate students really Get? Measuring language use in a naturalistic setting. The Canadian Modern Language Review/La Revue Canadienne Des Langues Vivantes, 69(1), 1-33.

Read, J. (Ed.). (2016). Post-admission language assessment of university students. Basel, Switzerland: Springer.

Reynebeau, M. (2017, December 30). Populisme is het nieuwe normaal. De Standaard.

Sen, A. (2000). Social Exclusion: Concept, Application and scrutiny. Manilla, Philippines: Asian Development Bank.

Serrano, R., Tragant, E., \& Llanes, À. (2012). A longitudinal analysis of the effects of one year abroad. Canadian Modern Language Review, 68(2), 138-163.

Spolsky, B. (2004). Language policy. Cambridge: Cambridge University Press.

Storch, N. (2009). The impact of studying in a second language (L2) medium university on the development of L2 writing. Journal of Second Language Writing, 18(2), 103-118.

Subtirelu, N. (2014). A language ideological perspective on willingness to communicate. System, 42, 120-132.

Swain, M. (2000). The output hypothesis and beyond: Mediating acquisition through collaborative dialogue. In J. P. Lantolf (Ed.), Sociocultural theory and second language learning (pp. 97-114). Oxford: Oxford University Press.

Swain, M., \& Deters, P. (2007). "New" mainstream SLA Theory: Expanded and enriched. The Modern Language Journal, 91, 820-836.

Tavakoli, P. (2018). L2 development in an intensive Study Abroad EAP context. System, 72(Supplement C), 62-74.

Treffers-Daller, J., Parslow, P., \& Williams, S. (2016). Back to Basics: How measures of lexical diversity can help discriminate between CEFR levels. Applied Linguistics, $1-27$.

Van Splunder, F. (2015). Taalstrijd. Over relaties tussen talen in de wereld, Europa, Nederland en Vlaanderen. Brussels: ASP.

Yang, J.-S. (2016). The effectiveness of study-abroad on second language learning: A meta-analysis. Canadian Modern Language Review, 72(1), 66-94. 